\title{
Identification of large-scale characteristic genes of Müllerian inhibiting substance in human ovarian cancer cells
}

\author{
SUK WOO NAM ${ }^{1}$, YUN SUNG JO ${ }^{2}$, JUNG WOO EUN ${ }^{1}$, JAE YEN SONG $^{2}$, KI SUNG RYU ${ }^{2}$, \\ JUNG YOUNG LEE ${ }^{1}$, JOON MO LEE ${ }^{2}$, DAVID T. MacLAUGHLIN ${ }^{3}$ and JANG HEUB KIM ${ }^{2}$ \\ Departments of ${ }^{1}$ Pathology, Microdissection Genomics Research Institute, and ${ }^{2}$ Obstetrics and Gynecology, \\ College of Medicine, The Catholic University of Korea, Seoul, Korea; ${ }^{3}$ Pediatric Surgical Research Laboratories, \\ Massachusetts General Hospital and Harvard Medical School, Boston, MA 02114, USA
}

Received December 5, 2008; Accepted January 26, 2009

DOI: 10.3892/ijmm_00000168

\begin{abstract}
The purpose of this study was to investigate the large-scale characteristic molecular signature of Müllerian inhibiting substance (MIS) in human ovarian cancer cells through expression genomics. To understand the comprehensive molecular mechanisms by which MIS inhibits ovarian cancer cell growth, we identified the large-scale characteristic molecular changes elicited by MIS in the human ovarian cancer cell line OVCAR-8, using DNA microarray analysis. Combined serial gene expression analysis from 0 to $96 \mathrm{~h}$ after MIS treatment of OVCAR-8 cells resulted in 759 genes which showed at least a 2 -fold change in overexpression or underexpression compared to non-treatment groups. Of the 759 outlier genes, 498 genes were mapped to known biological cellular processes, and the resultant major pathways included metabolism, signal transduction, cell growth and apoptosis. Among these pathways, 68 genetic elements were dissected as cell cycle-related genes induced by MIS. Although cellular phenotypic changes by MIS were observed after $24 \mathrm{~h}$ of treatment, the characteristic large-scale molecular changes were observed from 48 to $96 \mathrm{~h}$ of exposure to MIS. This finding may imply that the suppressive role of MIS on ovarian cancer cells could be cumulative in that the metabolic disturbance of MIS is followed by arrest at the G1/S cell cycle checkpoint. We suggest 759 outlier genes comprise the characteristic molecular signature of MIS, which may be responsible for the suppressive effect on OVCAR-8 cells. Although the precise biological mechanisms underlying these outlier genes should be validated, the genetic elements described herein provide promising therapeutic interventions for ovarian cancer.
\end{abstract}

Correspondence to: Dr Jang Heub Kim, Department of Obstetrics and Gynecology, College of Medicine, The Catholic University of Korea, \#62 Yeouido-dong, Yeongdeungpo-gu, Seoul 150-713, Korea E-mail: janghkim@catholic.ac.kr

Key words: Müllerian inhibiting substance, OVCAR-8 cell line, DNA microarray, cell cycle

\section{Introduction}

Müllerian inhibiting substance (MIS), also known as antiMüllerian hormone, is a member of the transforming growth factor- $\beta$ (TGF- $\beta$ ) superfamily of growth and differentiation response modifiers. Members of this family play an important role in mesenchymal-epithelial interaction, cell growth and proliferation, extracellular matrix production and tissue remodeling (1). In contrast to other members of this family, which exert a broad range of functions in multiple tissues, the principal function of MIS is to induce regression of the Müllerian ducts during sex differentiation in mammalian, avian and reptilian embryos $(2,3)$. The Müllerian duct, which forms from the coelomic epithelium, develops into the fallopian tubes, uterus, cervix, proximal vagina and surface epithelium of the ovary in females. MIS is produced in fetal and postnatal Sertoli cells in the testes at high levels which persist until puberty, after which, the concentration of MIS drops to basal levels, where it persists throughout life. In females, MIS is undetectable in the fetal and early postnatal ovary or in serum but becomes detectable in the granulosa cells of the developing ovarian follicles and in the serum of the adolescent and adult, and is never detected after menopause in healthy women (4-7). Mutations in MIS or the MIS type II (MISRII) receptor in humans cause persistent Müllerian duct syndrome, in which males retain Müllerian ducts in the presence of testes and the $\mathrm{Y}$ chromosome $(8,9)$. Transgenic female mice that overexpress MIS, demonstrate complete ablation of the ovary, along with undeveloped uterus and oviducts. In male mice overexpression of MIS leads to feminized genitalia, undescended testes, and poorly differentiated Wolffian ducts (10). In addition to its significant role in sexual development, MIS as a hormone probably plays an important role in the adult gonads of either sex (11); in fact recent evidence suggests other non-Müllerian sites of synthesis and responsiveness including motor neurons (12).

As a member of the TGF- $\beta$ family, MIS is thought to exert its effects through two distinct single membrane spanning serine-threonine receptors, types I and II. The binding of MIS to the type II receptor (MISRII) leads to heterodimerization with an MISRI, initiating a signaling cascade. There has been 
only one gene or the MIS type II receptor found in all animal species examined thus far. There are, however, several candidates for the MIS type I receptor (13). Since the type I receptors are nearly ubiquitously expressed, which type I receptor partners the type II receptor could be tissue and/or species specific. It is interesting to note that loss-of-function mutations created in mouse MISRII produce Leydig cell tumors in males and early follicular depletion in females $(11,14)$. Thus, lack of proper MIS signaling seems to predispose mice to uncontrolled division of MIS-responsive cells. This also implies that MIS may play a similar role in humans.

An increasing number of reports suggest that MIS is a multi-functional hormone in addition to its major role in sexual development in the embryo. Since most ovarian tumors originate from the surface epithelium of the ovary, which is of Mullerian duct origin $(15,16)$, the effect of MIS on the growth of ovarian cancer cells has been an area of intense study. Many previous studies have demonstrated that MIS inhibits the growth of Müllerian duct-derived tumors (17-19) and several cancer cell lines or primary cells in vitro (20-23). It was also demonstrated that OVCAR-8, an epithelial ovarian cancer cell line, expresses MISRII and responds to MIS by growth inhibition mediated through a retinoblastoma protein (p-RB)-independent mechanism involving the up-regulation of p16 at the protein level. This suggests that MIS requires p16 for growth inhibition in ovarian cancer cells, which in turn arrests cell growth at the G1/S phase and subsequently augments apoptosis (19). Although several reports have described the anti-neoplastic properties of MIS, little insight into the molecular nature of anti-tumor growth or apoptosis has been gained. Recently, DNA microarray technology has enabled the genome-wide analysis of gene transcript levels, and, as such, has yielded great insight into the molecular nature of cancer. A number of studies have demonstrated the usefulness of this technique for identifying novel cancer markers and for classifying human cancers at the molecular level for improved diagnosis and prediction of outcome (24-27).

Thus, to better understand the molecular mechanisms by which MIS inhibits the growth of ovarian cancer cells, we analyzed global transcript levels in the series context of different MIS treatment time points in OVCAR- 8 cells and identified characteristic genes which may reflect the molecular signature for the anti-tumor effect of MIS by utilizing largescale gene expression analysis of DNA microarray.

\section{Materials and methods}

Recombinant human MIS. Recombinant human MIS was purified, and its biological activity was confirmed in the Pediatric Surgical Research Laboratories at the Massachusetts General Hospital from serum-free and serum-containing conditioned media as described earlier (28).

Cells and cell culture. The human ovarian cancer cell line OVCAR-8 was grown in Dulbecco's modified Eagle's medium and $10 \%$ female fetal bovine serum, $1 \%$ penicillin/streptomycin and $1 \%$ L-glutamine for no more than 5 passages, and subcultures were initiated at $80 \%$ confluency. The cultures were maintained in a humidified atmosphere of $5 \% \mathrm{CO}_{2}$ at $37^{\circ} \mathrm{C}$.

Microarray fabrication. The 60-mers of the Human Oligolibrary $^{\mathrm{TM}}$ representing 18,664 LEADS $^{\mathrm{TM}}$ clusters plus 197 controls (GAPDH) were purchased from Compugen/ Sigma-Genosys and spotted onto a glass slide at the microarray core facility of the Microdissection Genomics Research Institute at the College of Medicine, The Catholic University of Korea as previously reported $(29,30)$.

Large-scale analysis of gene expression profiling by using oligonucleotide arrays. In brief, total cellular RNA was extracted from the vehicle control and MIS-treated cells using a TRIzol ${ }^{\circledR}$ reagent (Gibco, Grand Island, NY) and quantified using NanoDrop (NanoDrop Technologies, Wilmington, DE). In addition, RNA quality was checked by Bioanalyzer 2100 (Agilent Technologies, Santa Clara, CA), and intact RNA samples (260/280 ratio $>1.8)$ were used for hybridization. Human universal reference RNA (Stratagene, La Jolla, CA) was used as a reference RNA. From each total RNA sample, $20 \mu \mathrm{g}$ was primed with oligo-dT and labeled with Cy3-dUTP or Cy5-dUTP (New England Nuclear, Wilmington, MA) by reverse transcription. Labeled cDNA targets were concentrated to $\sim 15 \mu \mathrm{l}$ using Microcon-YM30 (Amicon, Bedford, MA). Hybridization was carried out at $42^{\circ} \mathrm{C}$ for $16 \mathrm{~h}$ using the MAUI Hybridization System (BioMicro Systems, Salt Lake City, UT). After hybridization, the microarray was washed twice with buffers containing $2 \mathrm{X}$ standard sodium citrate (SSC) and $0.1 \%$ SDS for $2 \mathrm{~min}$, $1 \mathrm{X} \mathrm{SSC}$ and $0.1 \% \mathrm{SDS}$ for $3 \mathrm{~min}, 0.2 \mathrm{X} \mathrm{SSC}$ for $3 \mathrm{~min}$, $0.05 \mathrm{X} \mathrm{SSC}$ for $2 \mathrm{~min}$, and finally rinsed with distilled water for $2 \mathrm{~min}$. This protocol was repeated twice in independent experiments on the OVCAR- 8 cells.

Scanning and data analysis. The arrays with hybridized targets were scanned using an Axon scanner, and the images were analyzed using GenePix ${ }^{\circledR}$ Pro 4.1 software (Molecular Devices, Sunnyvale, CA). Spots of poor quality identified by visual inspection were removed from further analysis. The resulting data collected from each array were submitted to the BioArray Software Environment (BASE) database at the microarray core facility at the Department of Pathology, College of Medicine, The Catholic University of Korea, Seoul, (http://genomics.catholic.ac.kr/). Data were normalized using the method of Linear Models for Microarray Data (LIMMA) and R-package for Statistics for Microarray Analysis (SMA). Spots $<50 \mu \mathrm{m}$ were eliminated for analysis unless otherwise specified. Pearson's correlation coefficient was calculated using the S-Plus program. Cluster and TreeView programs were used for visualization of data $(27,29,31)$. Pathway analysis was performed with ArrayXPath (http:www.snubi. org/software/ ArrayXPath/).

Methylthiazoletetrazolium (MTT) assay. Cells (3,000/well) were seeded in 96-well plates in OVCAR-8 media. After $24 \mathrm{~h}$, the cells were exposed to vehicle control or different concentrations $(5,10$, or $15 \mu \mathrm{g} / \mathrm{ml})$ of MIS for 24 and $48 \mathrm{~h}$. Cells were washed with PBS, and $100 \mu 1$ of MTT solution ( $5 \mathrm{mg} / \mathrm{ml}$ MTT stock in PBS diluted to $1 \mathrm{mg} / \mathrm{ml}$ with $10 \%$ 
DMEM) was added to each well. Cells were incubated for $4 \mathrm{~h}$ at $37^{\circ} \mathrm{C}$ at the end of which time $200 \mu 1 \mathrm{DMSO}$ (Sigma, St. Louis, MO) was added and incubated further for $30 \mathrm{~min}$ at room temperature in the dark. Optical densities at $550 \mathrm{~nm}$ were measured using an ELISA plate reader (Bio-Tek Instruments, Winooski, VT).

Cell cycle analysis. OVCAR-8 cells were exposed to MIS or vehicle control buffer for $24 \mathrm{~h}$, and the cells were collected by trypsinization. The cells were fixed with $100 \%$ methanol and stored for $30 \mathrm{~min}$ at $20^{\circ} \mathrm{C}$ and washed with PBS. Following centrifugation, the cells were resuspended in $1 \mathrm{ml}$ DNA staining solution (20 $\mu \mathrm{g} / \mathrm{ml}$ propidium iodide, $200 \mu \mathrm{g}$ / $\mathrm{ml}$ DNase-free RNase) and incubated in the dark at $37^{\circ} \mathrm{C}$ for 30 min. The cells were analyzed on a FACSVantage SE Flow Cytometer (Becton Dickinson, San Jose, CA). The forward scatter and red fluorescence $>600 \mathrm{~nm}$ were measured, and the results were analyzed using Cell Quest ${ }^{\mathrm{TM}}$ software and Modfit LT 3.0 program (Verity Software House, Topsham, ME).

Annexin $V$ analysis. MIS-treated cells were stained with Annexin V and propidium iodide (PI) using the Annexin VFITC Apoptosis Detection Kit I (BD Biosciences, San Diego, $\mathrm{CA}$ ) according to the manufacturer's protocol. Briefly, following drug treatment, $1 \times 10^{5}$ cells were pelleted and washed once with PBS and resuspended in $100 \mathrm{ml}$ of binding buffer [10 mM HEPES ( $\mathrm{pH} 7.4$ ), $150 \mathrm{mM} \mathrm{NaCl}, 5 \mathrm{mM}$ potassium chloride, $1 \mathrm{mM} \mathrm{MgCl}_{2}$, and $2 \mathrm{mM}$ calcium chloride]. Subsequently, $5 \mu \mathrm{l}$ of Annexin V-FITC and PI were added to the cells which were then incubated for $15 \mathrm{~min}$ at room temperature in the dark. After this incubation, $400 \mu 1$ of binding buffer was added, and cells were analyzed using a FACSVantage SE Flow Cytometer. Data analyses were conducted using Cell Quest software.

\section{Results}

MIS inhibits the growth of OVCAR-8 ovarian cancer cells and augments apoptosis. Before initiating experiments on MIS in ovarian cancer cells, we confirmed that the OVCAR-8 cells cultured in our laboratory expressed MISRII on their cell surface by inmunohistochemical staining and by Western blot analysis using an anti-MISRII antibody (data not shown). Growth inhibition of OVCAR-8 cells by MIS was evident at both 24 and $48 \mathrm{~h}$. As shown in Fig. 1, the cell viability was decreased to $65-85 \%$ of the control, and this inhibitory effect was dose-dependent. In order to determine whether this antigrowth activity was related to cell cycle regulation, the cell cycle phase distribution after MIS treatment was analyzed by flow cytometry (Fig. 2A). When cells were incubated with $10 \mu \mathrm{g} / \mathrm{ml}$ of MIS, the G0/G1 phase was significantly increased $11 \%$ at $24 \mathrm{~h}$ and $13 \%$ at $48 \mathrm{~h}$ compared to controls. This finding could be partially explained by the fact that MIS may induce $\mathrm{G} 1 / \mathrm{S}$ arrest at an early time point subsequently leading to cell death. In fact, induction of cell death by MIS in OVCAR-8 cells was detected but only at $48 \mathrm{~h}$ by FACS analysis of cells stained with Annexin V-FITC and PI (Fig. 2B).

Identification of large-scale molecular changes and characteristic molecular signature of MIS. To identify a

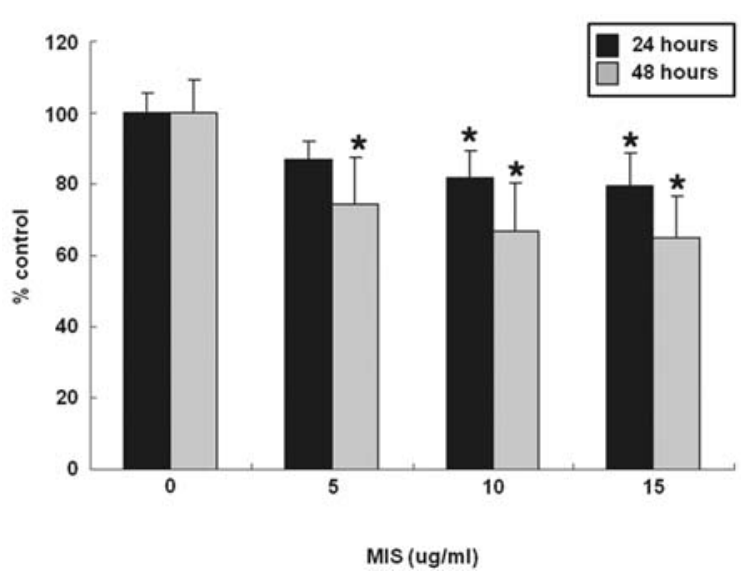

Figure 1. Inhibition of cell growth by MIS in OVCAR-8 ovarian cancer cells as assessed by the cell viability test using the MTT assay. OVCAR- 8 cells were treated with MIS at each indicated concentration for 24 and $48 \mathrm{~h}$. After incubation with or without MIS, cells were stained with MTT, and the absorbance was read at $550 \mathrm{~nm}$. Results are presented as a percentage of the control which was calculated using the equation: (mean absorbance of treated cells/mean absorbance of control cells) x 100. Data are expressed as the mean \pm standard deviation (SD) from four independent experiments. ${ }^{*} \mathrm{P}<0.05$ as compared to corresponding control cells.

molecular signature which is specifically induced by MIS, serial gene expression analysis using large-scale comprehensive DNA microarray experiments was conducted. Since MIS showed sustained growth inhibitory activity for at least $48 \mathrm{~h}$, OVCAR-8 cells were continuously treated with MIS for up to $96 \mathrm{~h}$, and the RNAs were harvested for microarray analysis at multiple time points as early as $6 \mathrm{~h}$. As shown in Fig. 3A, unsupervised hierarchical clustering of 9,073 genetic elements, which passed the minimum selection, and filtering criteria (see Materials and methods) resulted in two separate subclusters on the dendrogram; a short-term exposure group ( 0 to $24 \mathrm{~h}$ of MIS treatment) and a long-term exposure (48 to $96 \mathrm{~h}$ ) group. To identify genes that were continuously changing due to MIS action, mean values of the entire pool of genetic elements in non-treated cells ( $0 \mathrm{~h}$ of MIS) was subtracted from that of the long-term exposure group. The 759 outlier genes from this analysis were then re-examined in the expression data of the short-term exposure group and then shown as a heat map (Fig. 3B). Of 759 outlier genes, 416 genes were up-regulated and 343 genes were underexpressed in the long-term MIS exposure group compared to the controls. As shown in this figure, most of the outlier genes showed gradual and continuous changes from early MIS exposure with a few exceptions (Fig. 3B).

Molecular dissection of cell growth regulation by MIS through pathway mining analyses. By an in depth examination of the genes identified as candidate MIS targets, it was possible to locate downstream signaling pathways under the control of long-term MIS treatment of OVCAR- 8 cells. This process was accomplished by subjecting the 759 MIS-regulated genes to the pathway mining tool in the PANTHER Classification System (http://www.pantherdb.org/). Of the 759 outlier genes, 498 genes were mapped into known pathways, and the resultant biological processes were 
A)
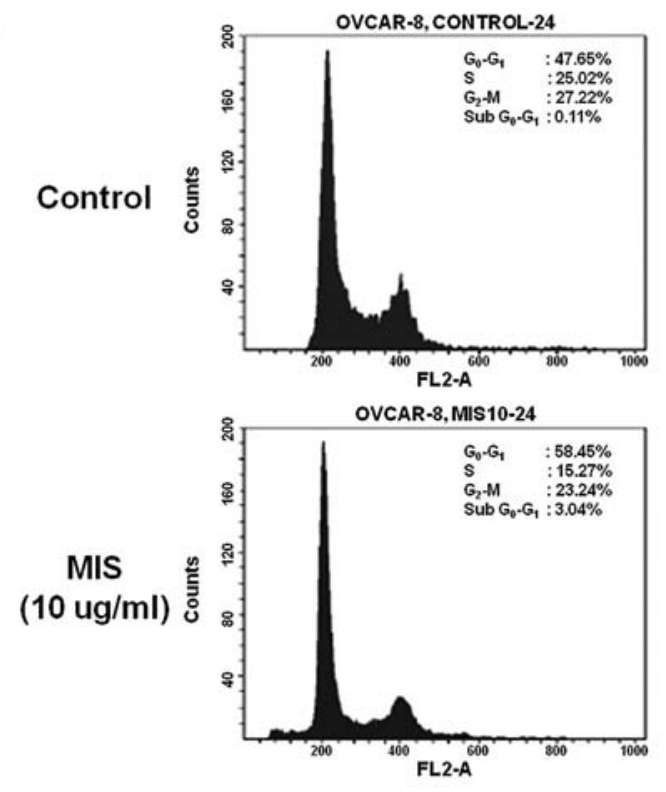

24 hours

B)

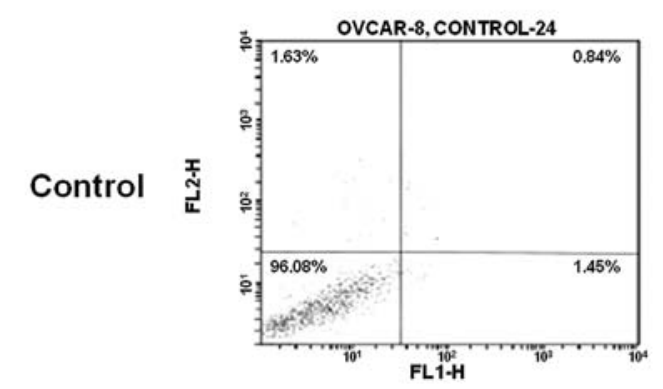

MIS $(10 \mathrm{ug} / \mathrm{ml})$

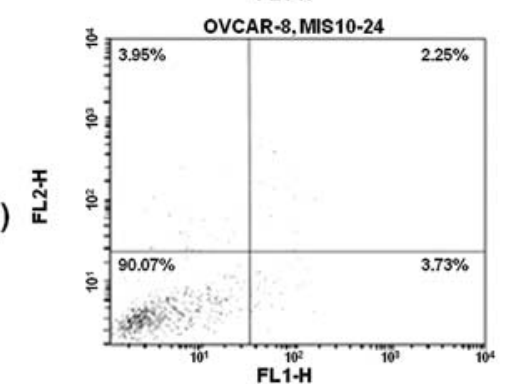

24 hours
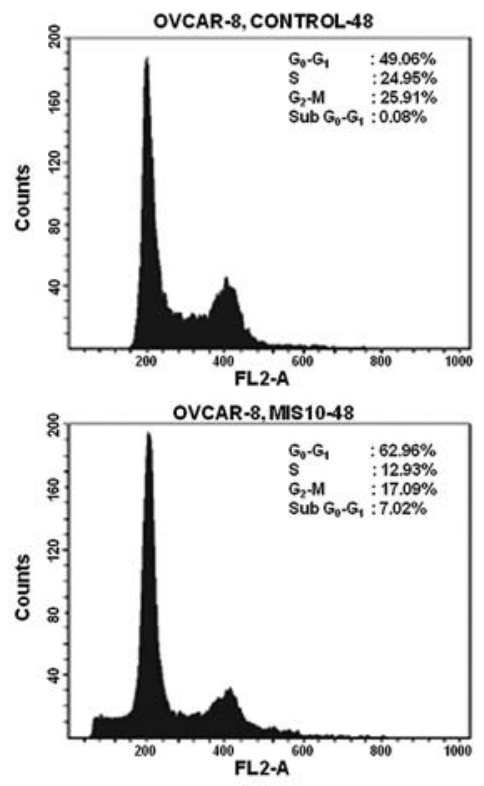

48 hours
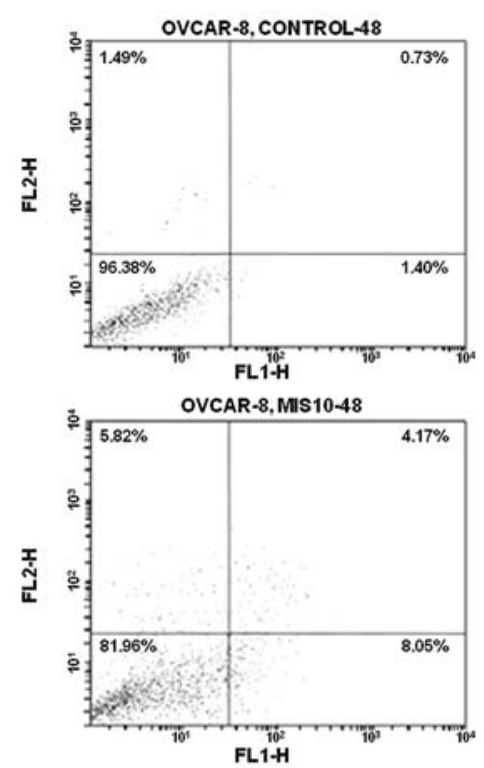

48 hours

Figure 2. Cell cycle arrest and induction of apoptosis by MIS in OVCAR-8 ovarian cancer cells. Cells were treated with MIS (10 $\mu \mathrm{g} / \mathrm{ml})$ for $24 \mathrm{and} 48 \mathrm{~h}$. (A) FACS analysis of the cell cycle. Cells were harvested with ice-cold PBS/EDTA, fixed in 95\% ethanol after incubation with MIS and stained with propidium iodide in an RNase solution with sodium citrate buffer for 30 min after which they were immediately analyzed. (B) Quantification of cells undergoing apoptosis. OVACR-8 cells were treated with $10 \mu \mathrm{g} / \mathrm{ml}$ of MIS for 24 and $48 \mathrm{~h}$, stained with Annexin V-FITC and PI, and analyzed by FACS. Quadrant rectangular dot grams from a representative of 3 independent experiments are shown.

categorized (Table I). As listed in Table I, the major processes in which the MIS characteristic genes are involved include signal transduction, nucleic acid, and protein metabolism and cell growth. In order to narrow these down to cell growth regulatory mechanisms which are mediated by MIS, we retrieved all genetic elements relating to cell growth processing from the 759 outlier genes (Fig. 4A). A total of 68 genetic elements were found as cell growth-related genes. Among these, 41 genes were underexpressed and 27 genes were overexpressed at long-term exposure time points. Furthermore, we dissected genetic elements, which are involved in the G1/S cell cycle checkpoint (Fig. 4B). The transcript level of p16 $6^{\text {INK4A }}$ did not change; however, the CDKs, particulary CDK2, 4 and 6 seemed to be downregulated by MIS as were E2F2, 3 and 4, binding partner of DP1. The downstream molecules such as MCMs, PCNA, RANGAP seemed to be suppressed by the down-regulation of the E2F/DP1 complex (Fig. 4B) whereas, HDAC5 and 6 exhibited a very strongly increased expression level from $48 \mathrm{~h}$ of MIS treatment.

In addition, we also dissected the cell death-related molecular signature of MIS from the 759 outlier genes 
Table I. Summary of the biological processes that are part of the characteristic molecular signature of MIS in OVCAR-8 cells.

\begin{tabular}{lc}
\hline Biological process & No. of genes \\
\hline Signal transduction & 108 \\
Nucleoside, nucleotide and nucleic acid metabolism & 90 \\
Protein metabolism and modification & 78 \\
Mesoderm and ectoderm development & 42 \\
Cell proliferation and differentiation & 38 \\
Cell cycle & 23 \\
Cell adhesion & 23 \\
Oncogenesis & 19 \\
Apoptosis & 18 \\
\hline
\end{tabular}

There were 759 genes which showed expression more than 2-fold above or below those of the untreated controls. Of the mapped genes, 498 were grouped by biological process.

(Fig. 5). Although this molecular signature should be validated and detailed regulatory cascade provided in apoptosis signal, it is obvious that caspase 1 , TNF receptor and MAP3K13, well known death-related factors, were overexpressed by MIS.

\section{Discussion}

In previous studies, it has been demonstrated that recombinant human MIS inhibits the growth of ovarian cancer cells and various primary tumors in vitro and in vivo (19,32-34). These findings are significant since the MIS type II receptor has been detected in an increasing number of human gynecological tumors (35). In addition, it also suggests that MIS inhibits growth inhibition through the activation of $\mathrm{p} 16$, a negative cell cycle regulator (19), and consequently disrupts cell cycle progression and leads to apoptosis. In order to confirm the anti-neoplastic activity of MIS, we assessed the growth inhibition and apoptosis of MIS on OVCAR-8 cells, which was previously demonstrated to express MISRII and to respond to MIS by growth inhibition. Our current results are in concordance with previous reports and confirmed that MIS induces anti-growth activity on OVACR-8 cells. It appears that, when compared to the cell cycle arrest data presented here, apoptosis seems to play a minor role in the effects of MIS on these cancer cells.

Accumulating evidence suggests that MIS augments the protein levels of the $\mathrm{p} 16^{\mathrm{INK} 4 \mathrm{~A}}$, a cyclin-dependent kinase (CDK) inhibitor and consequently down-regulates the CDK, particulary the cyclin D/CDK4 or 6 complex and inhibits G1/S cell cycle transition. Although similar cell cycle regulation by MIS has been investigated in other cancers $(20,36)$, the systemic molecular circuit of this cell cycle regulation in ovarian cancer still remains unknown. Furthermore, as several lines of evidence suggest that MIS is a multi-functional hormone, the comprehensive molecular signature which is mediated by MIS in cells needs to be elucidated.

In this study, we present the results of an initial microarray study designed to further expand upon the existing
A)

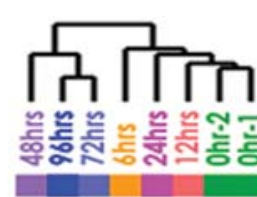

B)

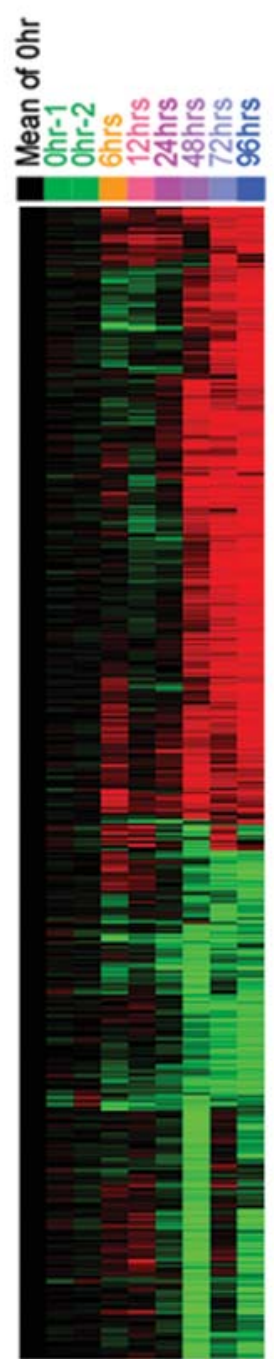

Figure 3. Differential gene expression profiling and identification of largescale molecular changes in MIS-treated OVCAR-8 cells. (A) Unsupervised hierarchical clustering of 9,073 genetic elements with minimum selection and filtering criteria (see Material and methods) resulted in two separate subclusters on dendrogram, short-term exposure group ( 0 to $24 \mathrm{~h}$ of MIStreatment) and long-term exposure (48 to $96 \mathrm{~h}$ ) group. (B) A significant subset of outlier genes were further narrowed by filtering genes showing expression changes due to MIS treatment of cells. Briefly, the mathematical comparisons of genes between $0 \mathrm{~h}$ and the 48- to 96-h time points were performed by selection of genes showing at least 2-fold changes induced by MIS treatment compared to non-treated control $(0 \mathrm{~h})$. This analysis resulted in the identification of 759 outlier genes that were significantly differentially expressed in MIS-treated cells. These elements were then visualized as a heat map where the red color indicates that expression levels of genetic elements are higher than the mean value of non-treatment, and green color indicates that expression levels of genetic elements are lower than the mean value of non-treatment.

hypotheses related to the MIS mechanism of action and to discover the role played by MIS in mediating other signaling, metabolic and cell cycle pathways in cancer cells. Although biological validation for the candidate MIS-regulated pathways reported here should be followed by Western blot analysis and real-time PCR, the genetic elements that we suggest as cell growth-related genes may further our understanding of the molecular insights into the cross-talk of intracellular signaling on cell growth regulations by MIS 

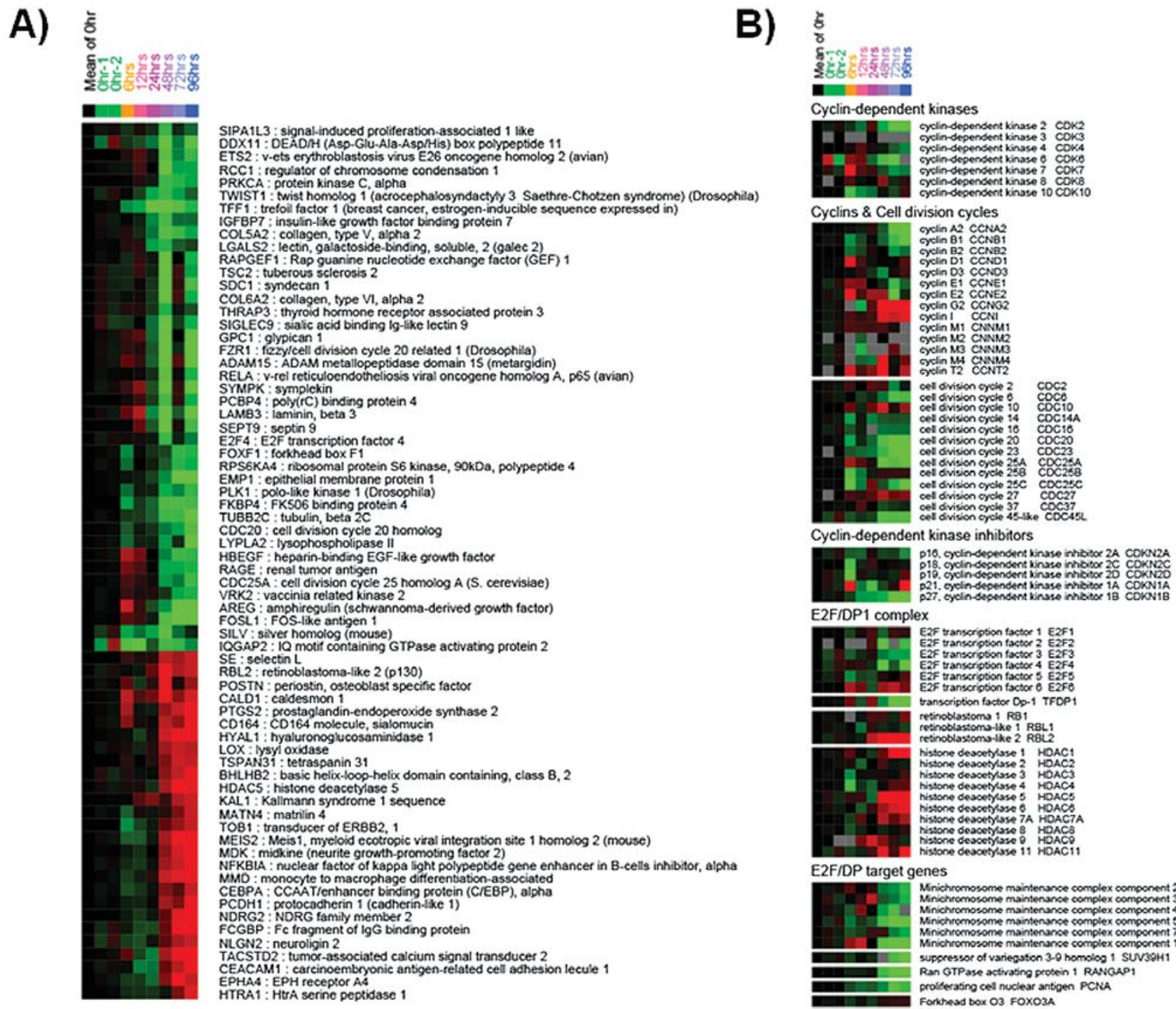

E2F/DP1 complex

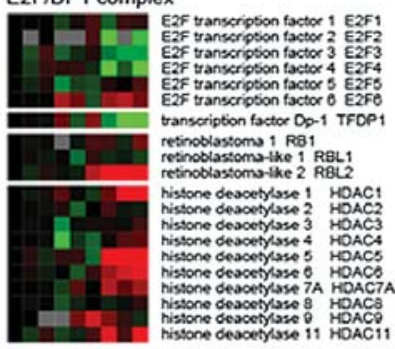

E2F/DP target genes

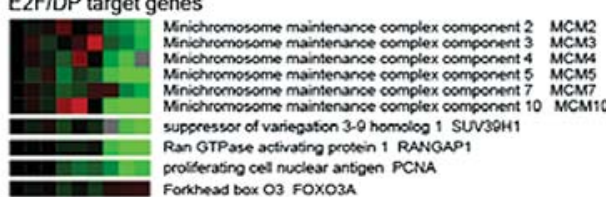

Figure 4. Selective expression profile of cell cycle-related genetic elements retrieved from 759 outliers. (A) A cell growth-associated molecular signature. Of 759 outlier genes, 68 genes were mapped into cell growth-related pathways such as cell growth and differentiation and cell cycle (Table I) through the PANTHER Classification System (http://www.pantherdb.org/). The expression patterns of genes were then visualized as a heat map. (B) Selective expression profile of genetic elements of G1/S transition of the cell cycle. The red color indicates that expression levels of genetic elements are higher than the mean value of non-treatment, and the green color indicates that expression levels of genetic elements are lower than mean value of non-treatment.

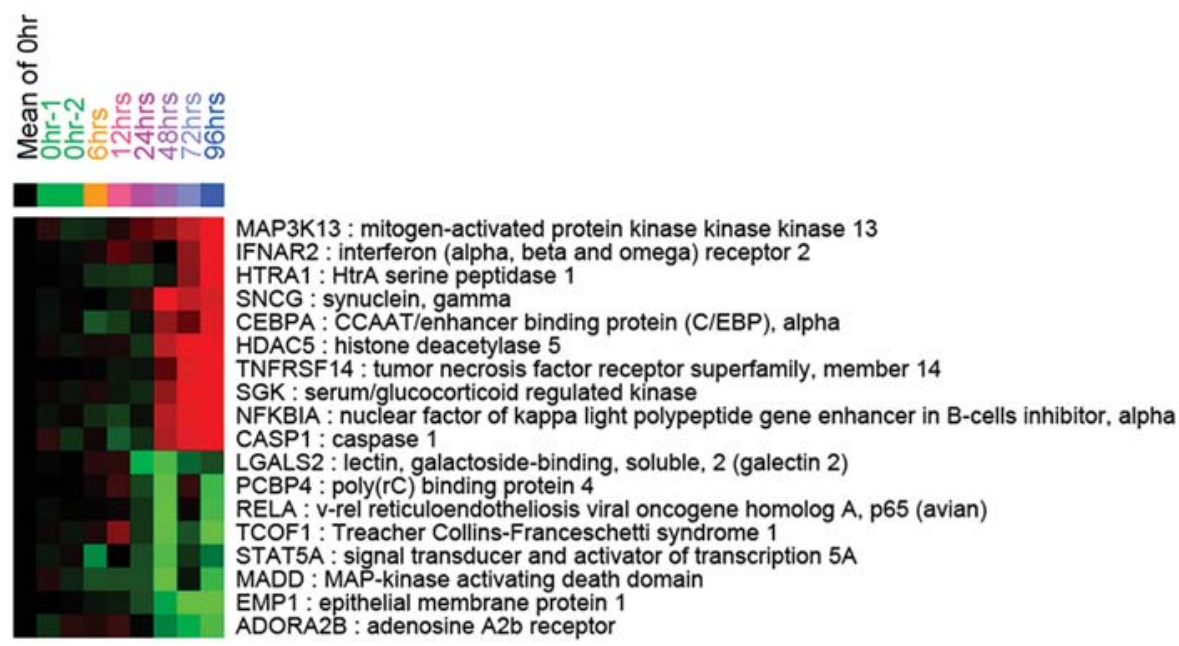

Figure 5. Selective expression profile of cell death-related genetic elements retrieved from 759 outliers. Of 759 outlier genes, 18 genes were mapped into apoptosis pathway (Table I) using the PANTHER Classification System (http://www.pantherdb.org/). The expression pattern of genes was then visualized as a heat map with the color indicators as described for the previous two figures. 
Regarding G1/S cell cycle regulation by MIS, we found that MIS did not induce most of the CDK inhibitors, but p19 INK4D and $\mathrm{p} 21^{\mathrm{Cip} 1}$ were slightly induced at $96 \mathrm{~h}$. It is interesting to know that the transcript level of p16 $16^{\mathrm{INK} 4 \mathrm{~A}}$ was not changed by MIS in a previous study (19) and the same result was obtained from our analysis (Fig. 4B). Of the CDKs, particularly CDK2, 4 and 6 seemed to be down-regulated by MIS. The E2F/DP1 complex is an important transcription factor regulated by the G1/S checkpoint. Our results indicated that E2F2, 3 and 4 were down-regulated by MIS. Consequently, many of the downstream target molecules of the E2F/DP1 transcription factor such as MCMs, PCNA, RANGAP seemed to be suppressed by this down-regulation of the E2F/DP1 complex (Fig. 4B). Histone deacetylases (HDACs), which are known to play a crucial role in chromatin remodeling, are also important co-suppressors of the E2F/DP1 complex such as Rb-family molecules. In our results, HDAC5 and 6 exhibited a very strongly increased expression level from $48 \mathrm{~h}$ of MIS treatment. This also indicates that the enhanced expression level of HDAC5 or 6 is cooperatively suppressive on the E2F/ DP1 transcription factor. In summary, our results suggest that the regulatory mechanism of MIS on the G1/S cell cycle checkpoint had a suppressive effect on CDKs and CDCs and the E2F/DP1 complex with transcriptional enhancement of certain HDAC family of E2F/DP1 co-suppressors, but did not seem to elevate transcript level of CDK inhibitors, a cell cycle negative regulator. The continuous changes in gene expression along with sequential time points of exposure to MIS suggest that gene expression changes may occur with early exposure to MIS, but transcriptomic expression characterized by MIS was induced after at least $48 \mathrm{~h}$ of long-term exposure. This indicated that the comprehensive molecular changes of the long-term exposure group were more unique than the shortterm group as this short-term group clustered with nontreatment control.

These novel findings clarify, at a molecular level, the manner in which MIS regulates the proliferation of cancer cells. It remains to be determined whether these pathways are MIS targets in normal fetal or adult tissues, but these data may facilitate the design of new drug targets for MIS in combination with other drugs for the treatment of ovarian cancer.

\section{Acknowledgements}

This work was supported by the Korea Ministry of Environment as 'The Eco-technopia 21 project' and by the Korea Science \& Engineering Foundation (KOSEF) through the Cell Death Disease Research Center at The Catholic University of Korea.

\section{References}

1. Massague $\mathrm{J}$ and Chen YG: Controlling TGF-beta signaling. Genes Dev 14: 627-644, 2000

2. MacLaughlin DT and Donahoe PK: Sex determination and differentiation. N Engl J Med 350: 367-378, 2004.

3. MacLaughlin DT and Donahoe PK: Mullerian inhibiting substance: an update. Adv Exp Med Biol 511: 25-40, 2002.

4. Munsterberg A and Lovell-Badge R: Expression of the mouse anti-mullerian hormone gene suggests a role in both male and female sexual differentiation. Development 113: 613-624, 1991.
5. Visser JA, McLuskey A, Verhoef-Post M, Kramer P Grootegoed JA and Themmen AP: Effect of prenatal exposure to diethylstilbestrol on Mullerian duct development in fetal male mice. Endocrinology 139: 4244-4251, 1998.

6. Lee MM, Donahoe PK, Hasegawa T, et al: Mullerian inhibiting substance in humans: normal levels from infancy to adulthood. J Clin Endocrinol Metab 81: 571-576, 1996.

7. Hudson PL, Dougas I, Donahoe PK, et al: An immunoassay to detect human mullerian inhibiting substance in males and females during normal development. J Clin Endocrinol Metab 70: 16-22, 1990.

8. Hoshiya M, Christian BP, Cromie WJ, et al: Persistent Mullerian duct syndrome caused by both a 27-bp deletion and a novel splice mutation in the MIS type II receptor gene. Birth Defects Res A Clin Mol Teratol 67: 868-874, 2003.

9. Belville C, Josso N and Picard JY: Persistence of Mullerian derivatives in males. Am J Med Genet 89: 218-223, 1999.

10. Behringer RR, Cate RL, Froelick GJ, Palmiter RD and Brinster RL: Abnormal sexual development in transgenic mice chronically expressing mullerian inhibiting substance. Nature 345: 167-170, 1990.

11. Behringer RR, Finegold MJ and Cate RL: Mullerian-inhibiting substance function during mammalian sexual development. Cell 79: 415-425, 1994.

12. Wang PY, Koishi K, McGeachie AB, et al: Mullerian inhibiting substance acts as a motor neuron survival factor in vitro. Proc Natl Acad Sci USA 102: 16421-16425, 2005.

13. Visser JA: AMH signaling: from receptor to target gene. Mol Cell Endocrinol 211: 65-73, 2003.

14. Durlinger AL, Kramer P, Karels B, et al: Control of primordial follicle recruitment by anti-Mullerian hormone in the mouse ovary. Endocrinology 140: 5789-5796, 1999.

15. Scully RE: Recent progress in ovarian cancer. Hum Pathol 1 73-98, 1970.

16. Scully RE: Pathology of ovarian cancer precursors. J Cell Biochem Suppl 23: 208-218, 1995.

17. Donahoe PK, Swann DA, Hayashi A and Sullivan MD: Mullerian duct regression in the embryo correlated with cytotoxic activity against human ovarian cancer. Science 205: 913-915, 1979.

18. Fuller AF Jr, Guy S, Budzik GP and Donahoe PK: Mullerian inhibiting substance inhibits colony growth of a human ovarian carcinoma cell line. J Clin Endocrinol Metab 54: 1051-1055, 1982.

19. Ha TU, Segev DL, Barbie D, et al: Mullerian inhibiting substance inhibits ovarian cell growth through an Rb-independent mechanism. J Biol Chem 275: 37101-37109, 2000.

20. Barbie TU, Barbie DA, MacLaughlin DT, Maheswaran S and Donahoe PK: Mullerian Inhibiting Substance inhibits cervical cancer cell growth via a pathway involving p130 and p107. Proc Natl Acad Sci USA 100: 15601-15606, 2003.

21. Gupta V, Carey JL, Kawakubo H, et al: Mullerian inhibiting substance suppresses tumor growth in the C3(1)T antigen transgenic mouse mammary carcinoma model. Proc Natl Acad Sci USA 102: 3219-3224, 2005.

22. Segev DL, Ha TU, Tran TT, et al: Mullerian inhibiting substance inhibits breast cancer cell growth through an NFkappa Bmediated pathway. J Biol Chem 275: 28371-28379, 2000.

23. Tran TT, Segev DL, Gupta V, et al: Mullerian inhibiting substance regulates androgen-induced gene expression and growth in prostate cancer cells through a nuclear factor-kappaBdependent Smad-independent mechanism. Mol Endocrinol 20: 2382-2391, 2006.

24. Alizadeh AA, Eisen MB, Davis RE, et al: Distinct types of diffuse large B-cell lymphoma identified by gene expression profiling. Nature 403: 503-511, 2000.

25. Golub TR, Slonim DK, Tamayo P, et al: Molecular classification of cancer: class discovery and class prediction by gene expression monitoring. Science 286: 531-537, 1999.

26. Sorlie T, Perou CM, Tibshirani R, et al: Gene expression patterns of breast carcinomas distinguish tumor subclasses with clinical implications. Proc Natl Acad Sci USA 98: 10869-10874, 2001.

27. Nam SW, Park JY, Ramasamy A, et al: Molecular changes from dysplastic nodule to hepatocellular carcinoma through gene expression profiling. Hepatology 42: 809-818, 2005

28. Lorenzo HK, Teixeira J, Pahlavan N, Laurich VM, Donahoe PK and MacLaughlin DT: New approaches for high-yield purification of Müllerian inhibiting substance improve its bioactivity. J Chromatogr B Analyt Technol Biomed Life Sci 766: 89-98, 2002 . 
29. Nam SW, Lee JH, Noh JH, et al: Comparative analysis of expression profiling of early-stage carcinogenesis using nodulein-nodule-type hepatocellular carcinoma. Eur J Gastroenterol Hepatol 18: 239-247, 2006

30. Noh JH, Ryu SY, Eun JW, et al: Identification of large-scale molecular changes of Autotaxin (ENPP2) knock-down by small interfering RNA in breast cancer cells. Mol Cell Biochem 288: 91-106, 2006.

31. Park JY, Kim SY, Lee JH, et al: Application of amplified RNA and evaluation of cRNA targets for spotted-oligonucleotide microarray. Biochem Biophys Res Commun 325: 1346-1352, 2004.

32. Masiakos PT, MacLaughlin DT, Maheswaran S, et al: Human ovarian cancer, cell lines, and primary ascite cells express the human Mullerian inhibiting substance (MIS) type II receptor, bind, and are responsive to MIS. Clin Cancer Res 5: 3488-3499, 1999.
33. Stephen AE, Masiakos PT, Segev DL, Vacanti JP, Donahoe PK and MacLaughlin DT: Tissue-engineered cells producing complex recombinant proteins inhibit ovarian cancer in vivo. Proc Natl Acad Sci USA 98: 3214-3219, 2001.

34. Stephen AE, Pearsall LA, Christian BP, Donahoe PK, Vacanti JP and MacLaughlin DT: Highly purified mullerian inhibiting substance inhibits human ovarian cancer in vivo. Clin Cancer Res 8: 2640-2646, 2002.

35. Bakkum-Gamez JN, Aletti G, Lewis KA, et al: Mullerian inhibiting substance type II receptor (MISIIR): a novel, tissuespecific target expressed by gynecologic cancers. Gynecol Oncol 108: 141-148, 2008

36. Renaud EJ, MacLaughlin DT, Oliva E, Rueda BR and Donahoe PK Endometrial cancer is a receptor-mediated target for Mullerian Inhibiting Substance. Proc Natl Acad Sci USA 102: 111-116, 2005. 